\title{
Thermodynamic stability and structure of copper oxide surfaces: A first-principles investigation
}

\author{
Aloysius Soon, ${ }^{1, *}$ Mira Todorova, ${ }^{1}$ Bernard Delley, ${ }^{2}$ and Catherine Stampfl ${ }^{1}$ \\ ${ }^{1}$ School of Physics, The University of Sydney, Sydney, New South Wales 2006, Australia \\ ${ }^{2}$ Paul-Scherrer-Institut, CH-5232 Villigen PSI, Switzerland
}

(Received 29 October 2006; published 21 March 2007)

\begin{abstract}
To obtain insight into the structure and surface stoichiometry of copper-based catalysts in commercially important chemical reactions such as the oxygen-assisted water-gas shift reaction, we perform densityfunctional theory calculations to investigate the relative stability of low-index copper oxide surfaces. By employing the technique of "ab initio atomistic thermodynamics," we identify low-energy surface structures that are most stable under realistic catalytic conditions are found to exhibit a metallic character. Three surfaces are shown to have notably lower surface free energies compared to the others considered and could be catalytically relevant; in particular, under oxygen-rich conditions, they are the $\mathrm{Cu}_{2} \mathrm{O}(110)$ : $\mathrm{CuO}$ surface, which is terminated with both $\mathrm{Cu}$ and $\mathrm{O}$ surface atoms, and the $\mathrm{Cu}_{2} \mathrm{O}(111)-\mathrm{Cu}_{\mathrm{CuS}}$ surface, which contains a surface (coordinatively unsaturated) $\mathrm{Cu}$ vacancy, while for the oxygen-lean conditions, the $\mathrm{Cu}_{2} \mathrm{O}(111)$ surface with a surface interstitial $\mathrm{Cu}$ atom is found to be energetically most favorable, highlighting the importance of defects at the surface.
\end{abstract}

DOI: 10.1103/PhysRevB.75.125420

PACS number(s): 68.47.Gh, 81.65.Mq, 68.43.Bc

\section{INTRODUCTION}

Despite numerous experimental and theoretical studies, many surface properties of metal oxides are not well understood. Metal oxide surfaces react with gases or solution and can behave as a catalyst, or in some cases, a support for a catalyst. The challenge is to understand the factors controlling the adsorption and reactivity of the adsorbates on the surface. Clean metal oxide surfaces present two distinct, potentially active sites: cationic and anionic sites. ${ }^{1}$ Electronrich molecules, also known as Lewis bases, will interact with cationic sites, and electron-poor ones, which are known as Lewis acids, will interact with anionic sites. Lowcoordinated sites show a general trend of being more reactive than sites of high coordination. ${ }^{2}$

Besides the typical acid-base reactions and coordination, the reduction-oxidation (redox) mechanism also controls adsorption behavior. When an oxide deviates from the bulk stoichiometry due to the presence of defects such as vacancies or adatoms, the formal oxidation state of surface atoms varies and the (re) distribution of electron charges becomes a determining factor. For stoichiometric (i.e., without the presence of defects) metal oxides with metal cations in their highest formal oxidation states, a common picture is that the metal atoms lose most of their valence electrons, exhibiting a semiconducting or insulating behavior. There are, however, exceptions, such as the oxides of ruthenium and vanadium, which are known to exhibit a metallic character. The valence band will have a predominantly bonding character, with the majority of these states localized on the $\mathrm{O}$ atoms. The conduction band, on the other hand, has a predominantly antibonding character, with states mainly localized on the metal sites. ${ }^{3}$ In contrast to redox reactions, acid-base reactions do not modify the formal oxidation states of the atoms involved.

Although the above-mentioned mechanisms are rather simplistic, they are helpful in elucidating the possible role of defects in the promotion of surface reactions, as studied by first-principles density-functional theory (DFT) calculations.
The behavior of a catalyst also depends on the environment. Investigations, for example, of the dependence on temperature and pressure of the system can be carried out by applying so-called $a b$ initio atomistic thermodynamics. ${ }^{4}$

In recent years, the water-gas shift (WGS) reaction has been widely investigated in research related to fuel cell technology because of its potential to purify the hydrogen gas used in fuel cells. Fuel cells convert the chemical energy of fuel into electrical and thermal energies. For fuel cells operating with hydrogen as fuel (such as the polymer electrolyte membrane fuel cell), the WGS reaction is a critical step in fuel processors for preliminary $\mathrm{CO}$ reduction and additional hydrogen generation prior to the $\mathrm{CO}$ preferential oxidation or methanation step. Numerous experimental studies have addressed the properties and behavior of catalysts prepared for fuel cell applications (see, e.g., Refs. 5-9).

$\mathrm{Cu} / \mathrm{ZnO} / \mathrm{Al}_{2} \mathrm{O}_{3}$ catalysts have long been used in the WGS reaction. ${ }^{10-12}$ Recently, Utaka et al. ${ }^{10}$ found that in the presence of about $2 \% \mathrm{O}_{2}$, the $\mathrm{Cu} / \mathrm{ZnO} / \mathrm{Al}_{2} \mathrm{O}_{3}$ catalyst attained almost $90 \%$ conversion of $\mathrm{CO}$ to $\mathrm{CO}_{2}$ at the reaction temperature of $420 \mathrm{~K}$ while maintaining its selectivity. This so-called oxygen-assisted WGS (OWGS) reaction [Eq. (1)] was also investigated over a $\mathrm{Cu}-\mathrm{Pd}$ bimetallic catalyst, supported over $\mathrm{CeO}_{2}{ }^{13}$ This $\mathrm{Cu}$-based catalyst also exhibited a high CO conversion, close to $100 \%$,

$$
(1+x) \mathrm{CO}+\mathrm{H}_{2} \mathrm{O}+\frac{x}{2} \mathrm{O}_{2} \rightarrow(1+x) \mathrm{CO}_{2}+\mathrm{H}_{2} .
$$

Although the $\mathrm{Cu}$-based catalyst (on various supports) has been intensely investigated, it is still poorly understood, especially in relation to its catalytically active sites and structural morphology. To model the $\mathrm{Cu} / \mathrm{ZnO} / \mathrm{Al}_{2} \mathrm{O}_{3}$ catalyst as a well-defined single-crystal surface, the $\mathrm{O} / \mathrm{Cu}(111)$ system has often been used to understand and study this catalyst. It has been investigated both theoretically ${ }^{14}$ and experimentally. ${ }^{15-25}$ It is reported, from experiments, that the surface structure of oxidized copper resembles that of 
$\mathrm{Cu}_{2} \mathrm{O}(111){ }^{25-27}$ These experiments also suggest that other oxide phases, such as $\mathrm{CuO}$ and $\mathrm{Cu}_{3} \mathrm{O}_{2}$, could possibly coexist on the surface. To facilitate our understanding of this important catalyst, we have recently conducted a study of the interaction of oxygen with the $\mathrm{Cu}(111)$ surface. ${ }^{28}$ This interaction is considered pivotal as a small amount of oxygen has been shown to promote the WGS reaction over copper-based catalysts. We found that upon increasing the chemical potential of oxygen, surface oxides are likely to be a precursor phase before the onset of the bulk phase, where the bulk phase is the thermodynamically most stable one under oxygen-rich and elevated temperature conditions. Recognizing the importance of having a firm understanding of the surface structure of this catalyst, we investigate in detail, in this paper, various terminations of low-index $\mathrm{Cu}_{2} \mathrm{O}$ surfaces and seek to comprehend how they might play a role in industrially relevant chemical reactions such as the WGS reaction.

\section{CALCULATION METHODOLOGY}

\section{A. Density-functional theory: Basis set and convergence}

All calculations are performed using density-functional theory (DFT) and the generalized gradient approximation (GGA) of Perdew et al. ${ }^{29}$ for the exchange-correlation functional as implemented in the all-electron $\mathrm{DMol}^{3}$ code. The $\mathrm{DMol}^{3}$ method employs fast converging three-dimensional numerical integrations to calculate the matrix elements occurring in the Ritz variational method. The wave functions are expanded in terms of a double-numerical quality localized basis set with a real-space cutoff of 9 bohr. Polarization functions and scalar-relativistic corrections are incorporated explicitly. More details can be found elsewhere. ${ }^{30,31}$

To simulate the various $\mathrm{Cu}_{2} \mathrm{O}$ surfaces, we use supercells containing symmetric slabs (with inversion symmetry) with 15-19 atomic layers (ranging from 30-56 atoms) and a 30-40 ̊ vacuum region between adjacent slabs. All surfaces are fully relaxed while keeping the inner-most three center layers fixed at bulk values. For all orientations we have verified that using thicker slabs does not result in any significant changes (i.e., $\leqslant 1 \mathrm{meV} / \AA^{2}$ for the surface energy). The Brillouin-zone (BZ) integration is performed using Monkhorst-Pack grids of $(8 \times 8 \times 1),(12 \times 6 \times 1)$, and $(12 \times 12 \times 1)$ with 10,18 , and $42 \mathbf{k}$ points in the irreducible part of the BZ for the (111), (110), and (100) surfaces, respectively. With these basis sets, the surface energies of different oxide surfaces are converged to within $2 \mathrm{meV} / \AA^{2}$ regarding $\mathbf{k}$ points and real-space cutoff parameter. The description of the basis set used is further elaborated on in Ref. 28.

\section{B. Atomistic thermodynamics}

In order to describe the thermodynamic stability of $\mathrm{Cu}_{2} \mathrm{O}$ surfaces in an oxygen environment, we use the results of DFT total-energy calculations as input to atomistic thermodynamics considerations, ${ }^{4,28,32-36}$ which treat the effect of the surrounding gas phase via contact with a corresponding reservoir. In equilibrium with such a reservoir, the most stable surface structure in the constant pressure and temperature $(p, T)$ ensemble minimizes the surface free energy, which is defined as

$$
\gamma\left(\left\{p_{i}\right\}, T\right)=\frac{1}{A}\left[G-\sum_{i} N_{i} \mu_{i}\left(p_{i}, T\right)\right]
$$

Here, $G$ is the Gibbs free energy of the solid with the surface area $A . \mu_{i}\left(p_{i}, T\right)$ is the chemical potential of the various species $i$ present in the system, i.e., in this case $i=\mathrm{Cu}$ and O. $N_{i}$ is the number of atoms of the $i$ th component in the system. For ambient temperatures and sufficiently large particles, bulk $\mathrm{Cu}_{2} \mathrm{O}$ may be assumed to be a second thermodynamic reservoir with which the surface is equilibrated. This constrains the chemical potentials of $\mathrm{Cu}$ and $\mathrm{O}$ to the Gibbs free energy of the bulk $\mathrm{Cu}_{2} \mathrm{O}, g_{\mathrm{Cu}_{2} \mathrm{O}}^{\text {buk }}$ (where the small $g$ denotes the Gibbs free energy per formula unit), which allows one to express Eq. (2) solely as a function of $\mu_{\mathrm{O}}$. Then, the remaining quantities to be determined for the calculation of the surface free energy are then the chemical potential of the oxygen gas phase, $\mu_{\mathrm{O}}$, as well as the difference in Gibbs free energies of the slab and bulk $\mathrm{Cu}_{2} \mathrm{O}$.

The computation of $\mu_{\mathrm{O}}$ is straightforward, as $\mu_{\mathrm{O}}$ is fixed by the surrounding gas phase reservoir, which may be well approximated as an ideal gas. Ideal-gas laws then relate the chemical potential to pressure and temperature, ${ }^{32-35}$ and we will convert the dependence of the surface free energy on $\mu_{\mathrm{O}}(p, T)$ into more intuitive pressure scales at $T=300,600$, and $900 \mathrm{~K}$. The second contribution to $\gamma(p, T)$, i.e., the Gibbs free energy difference of the bulk phase and the slab, receives contributions from changes in the vibrational and configurational degrees of freedom at the surface, from the $p V$ term, and as leading contribution, from the difference in total energies. From dimensional analysis, the $p V$ term can be neglected. ${ }^{32}$ The configurational contribution for a system such as $\mathrm{Cu}_{2} \mathrm{O}$ can be first neglected for a study that aims at a first, rather coarse, comparison of different $(1 \times 1)$ surface terminations.

The vibrational contribution can be obtained from first principles using the computed phonon density of states (DOS) at the surface and in the bulk. However, for simplicity, by applying the Einstein approximation ${ }^{37}$ to the phonon DOS, one can estimate the order of magnitude of this contribution. We adopt the approach used in Ref. 32 and perform a frozen-phonon calculation for each atom type in a $(1 \times 1 \times 1)$ unit cell of $\mathrm{Cu}_{2} \mathrm{O}$ at the $\Gamma$ point. Taking the average of the vibrational modes due to each $\mathrm{Cu}$ and $\mathrm{O}$, we obtain the characteristic vibrational modes for $\mathrm{Cu}, \bar{\omega}_{\mathrm{Cu}}$ $(20 \mathrm{meV})$, and $\mathrm{O}, \bar{\omega}_{\mathrm{O}}(62 \mathrm{meV})$. Coupled modes between $\mathrm{Cu}$ and $\mathrm{O}$ are neglected. The $(1 \times 1 \times 1)$ bulk $\mathrm{Cu}_{2} \mathrm{O}$ cell contains four $\mathrm{Cu}$ atoms and two $\mathrm{O}$ atoms. The characteristic vibrational modes for $\mathrm{Cu}$ and $\mathrm{O}$ are not changed by increasing this unit cell to a $(3 \times 3 \times 3)$ cell. A $\pm 50 \%$ variation of these bulk values is used to estimate the contribution of the surface $\mathrm{Cu}$ and $\mathrm{O}$ atoms, allowing us to define an upper and lower limit to the change in vibrational contribution in the free energy, 


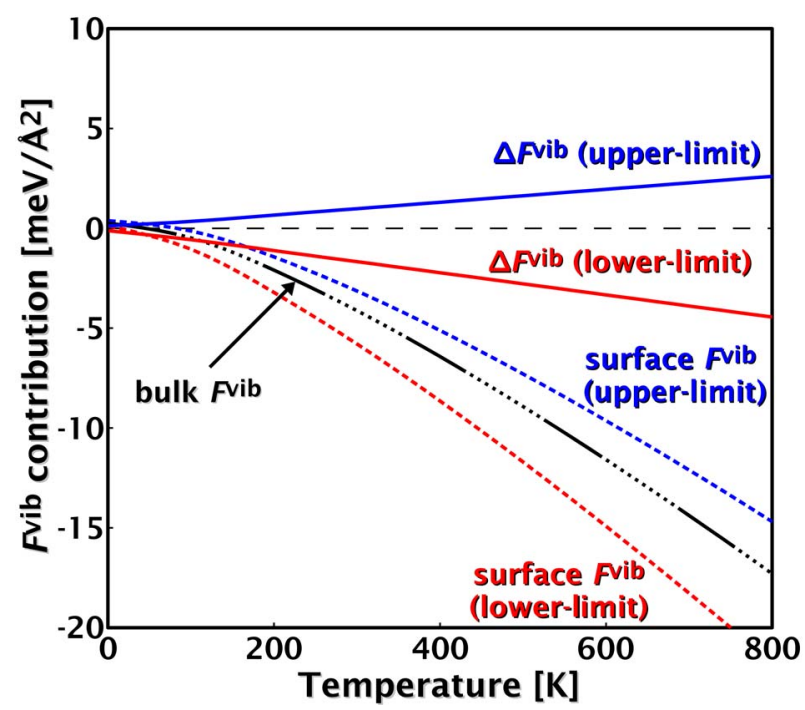

FIG. 1. (Color online) An estimate of the change in the vibrational contribution, $\Delta F^{\mathrm{vib}}$ (solid lines) to a surface structure, cf. Eq. (3), in a temperature range of $0-800 \mathrm{~K}$. The characteristic vibrational modes for $\mathrm{Cu}, \bar{\omega}_{\mathrm{Cu}}$, and $\mathrm{O}, \bar{\omega}_{\mathrm{O}}$, are approximated in an Einstein model, and the vibrational modes at the surface are estimated by varying the bulk modes by $\pm 50 \%$. From the plot, this contribution is well within $\pm 5 \mathrm{meV} / \AA^{2}$ for the considered range of temperatures. The absolute vibrational contribution to the bulk free energy, $F^{\mathrm{vib}}$, is shown as the dot-dashed line and the upper and lower limits (corresponding to $\pm 50 \%$ variation of this) are shown as the dashed lines.

$$
\begin{aligned}
\Delta F^{\mathrm{vib}}= & \frac{1}{A}\left[2\left\{F^{\mathrm{vib}}\left(T, \bar{\omega}_{\mathrm{Cu}}^{\mathrm{surf}}\right)-F^{\mathrm{vib}}\left(T, \bar{\omega}_{\mathrm{Cu}}^{\mathrm{bulk}}\right)\right\}\right. \\
& \left.+\left\{F^{\mathrm{vib}}\left(T, \bar{\omega}_{\mathrm{O}}^{\mathrm{surf}}\right)-F^{\mathrm{vib}}\left(T, \bar{\omega}_{\mathrm{O}}^{\text {bulk }}\right)\right\}\right] .
\end{aligned}
$$

The absolute vibrational contribution to the free energy calculated in Eq. (3) is given by

$$
F^{\mathrm{vib}}(T, \bar{\omega})=\frac{1}{2} \hbar \bar{\omega}+k_{B} T \ln \left(1-e^{-\hbar \bar{\omega} / k_{B} T}\right)
$$

where $\hbar, k_{B}$, and $T$ are the reduced Planck's constant, Boltzmann's constant, and the temperature of the system, respectively. We use Eq. (3) to plot the change in the vibrational contribution to the surface free energy in Fig. 1. $F^{\mathrm{vib}}\left(T, \bar{\omega}_{X}^{\text {surf }}\right)$ and $F^{\mathrm{vib}}\left(T, \bar{\omega}_{X}^{\text {bulk }}\right)$ are the vibrational contribution to the surface free energy due to a surface and a bulk atom, respectively, with $X$ being either $\mathrm{Cu}$ or $\mathrm{O}$. These plotted values are comparable to the values reported for PdO (Ref. 38) and $\mathrm{RuO}_{2}$ (Ref. 32) and are well within $\pm 5 \mathrm{meV} / \AA^{2}$ for temperatures up to $800 \mathrm{~K}$. Thus, for the present study, vibrations may be neglected without affecting the physical conclusions drawn.

\section{RESULTS AND DISCUSSION}

\section{A. Bulk $\mathrm{Cu}_{2} \mathrm{O}, \mathrm{Cu}$, and the $\mathrm{O}_{2}$ molecule}

$\mathrm{Cu}_{2} \mathrm{O}$ crystallizes in a cuprite structure with space group $P n \overline{3} m$. ${ }^{39}$ There are two formula units of $\mathrm{Cu}_{2} \mathrm{O}$ in this unit

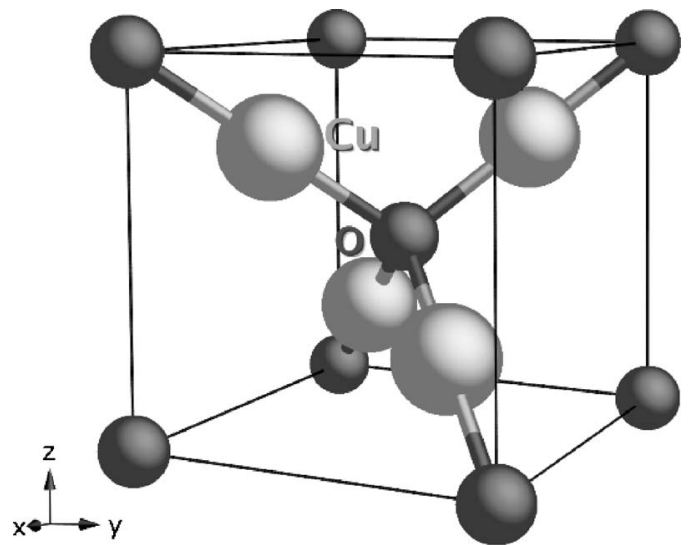

FIG. 2. The cuprite bulk unit cell of $\mathrm{Cu}_{2} \mathrm{O}$. Small dark spheres indicate oxygen atoms and large light ones, $\mathrm{Cu}$ atoms.

cell with two inequivalent atoms: an $\mathrm{O}$ atom at $(0,0,0)$ and a $\mathrm{Cu}$ atom at $(1 / 4,1 / 4,1 / 4)$, as shown in Fig. 2. Each $\mathrm{Cu}$ atom is linearly coordinated to two oxygen atoms, and all oxygen atoms are tetrahedrally surrounded by four $\mathrm{Cu}$ atoms. $\mathrm{Cu}_{2} \mathrm{O}$ is a direct band-gap semiconductor, with a calculated band gap of $0.64 \mathrm{eV} .^{28}$ The well-established experimental value $^{37}$ is $2.17 \mathrm{eV}$ and is typically significantly larger than that obtained by DFT-GGA (or as well as by the localdensity approximation). We found the optimized lattice constant, bulk modulus, and enthalpy of formation for cuprous oxide to be $4.32 \AA$, $103.7 \mathrm{GPa}$, and $1.24 \mathrm{eV}$, respectively, as previously reported. ${ }^{28}$ The corresponding experimental values are $4.27 \AA, 112 \mathrm{GPa}$, and $1.75 \mathrm{eV} .{ }^{40-43}$ The theoretical enthalpy of formation, $\mathrm{H}_{\mathrm{Cu}_{2} \mathrm{O}}$, ${ }^{28}$ was found to be considerably smaller than the experimental value and this can, in part, be attributed to the overestimation of the binding energy of the oxygen molecule.

From our previous work, ${ }^{28}$ the optimized lattice constant of bulk copper (neglecting zero-point vibrations) is $3.64 \AA$, which agrees very well with the established experimental value of $3.61 \AA .{ }^{37}$ The computed bulk modulus and cohesive energy are $136 \mathrm{GPa}$ and $3.45 \mathrm{eV}$, being in excellent agreement with the experimental values of $137 \mathrm{GPa}$ and $3.49 \mathrm{eV},{ }^{37}$ respectively. The slight overestimation of the lattice constant and the underestimation of the bulk modulus are in line with analogous studies for other transition metals. ${ }^{44-46}$

Spin-unrestricted calculations using nonspherical densities are performed to study the oxygen atom and molecule. To achieve excellent numerical accuracy, the real-space cutoff for the calculation of both the oxygen atom and oxygen molecule is increased to $20 \mathrm{bohr}$, with the largest basis set available in the $\mathrm{DMol}^{3}$ code. The binding energy of $\mathrm{O}_{2}$ is calculated to be $3.04 \mathrm{eV} / \mathrm{O}$ atom, while the bond length and vibrational frequency are $1.22 \AA$ and $1527 \mathrm{~cm}^{-1}$, respectively, in excellent agreement with other theoretical results. ${ }^{14,29,44}$ From experiments, the corresponding values ${ }^{47}$ are $2.56 \mathrm{eV} /$ atom, $1.21 \AA$, and $1580 \mathrm{~cm}^{-1}$. The typical overestimation of DFT-GGA is observed in the binding energy. The calculated values presented here are indicative of wellconverged DFT-GGA calculations, and since our interest lies mainly in the relative stability of various structures, this 

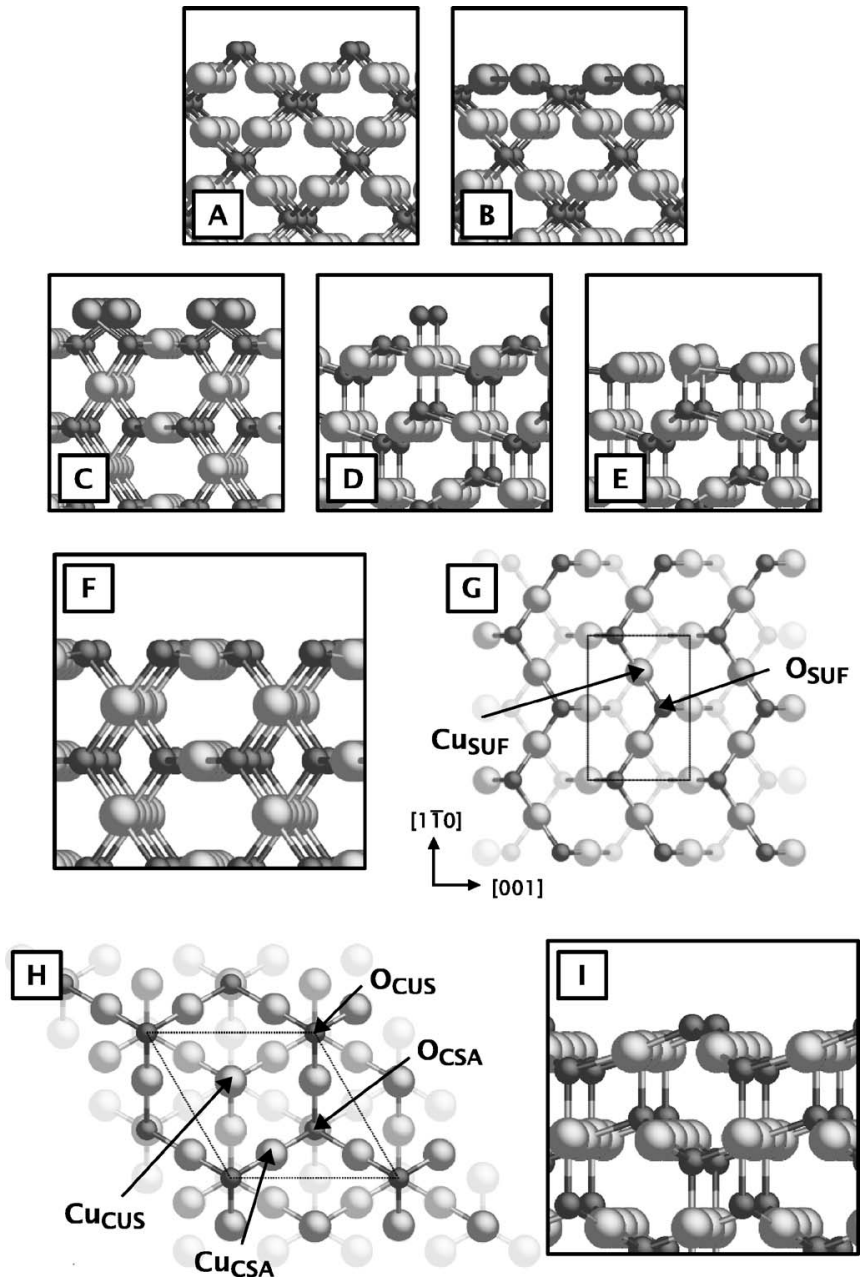

FIG. 3. Surface structures of $\mathrm{Cu}_{2} \mathrm{O}$. (A) and (B) show the side view of $\mathrm{Cu}_{2} \mathrm{O}(100): \mathrm{O}$ and $\mathrm{Cu}_{2} \mathrm{O}(100): \mathrm{Cu}$, respectively. (C) shows the side-view of $\mathrm{Cu}_{2} \mathrm{O}(110): \mathrm{Cu}$ and $(\mathrm{F})$ and $(\mathrm{G})$ show the side view (along the [1힐 direction) and top view of $\mathrm{Cu}_{2} \mathrm{O}(110): \mathrm{CuO}$, respectively. The side view of $\mathrm{Cu}_{2} \mathrm{O}(111): \mathrm{O}$ and $\mathrm{Cu}_{2} \mathrm{O}(111): \mathrm{Cu}$ are shown in (D) and (E), and (H) and (I) show the top and side views of $\mathrm{Cu}_{2} \mathrm{O}(111)$. Copper atoms are shown as large circles, and oxygen atoms as the smaller circles. The surface unit cell for the (110) and (111) surfaces are shown in $(\mathrm{G})$ and $(\mathrm{H})$.

overbinding will not affect the qualitative conclusions in this paper.

\section{B. Low-index $\mathrm{Cu}_{2} \mathrm{O}$ surfaces}

There are three low-index surfaces for $\mathrm{Cu}_{2} \mathrm{O}$, namely, the (100), (110), and (111) surfaces, each with a different number of $(1 \times 1)$ surface terminations. For the $\mathrm{Cu}_{2} \mathrm{O}(100)$ surface, we considered the O-terminated [i.e., $\mathrm{Cu}_{2} \mathrm{O}(100)$ : O] or $\mathrm{Cu}$-terminated [i.e., $\mathrm{Cu}_{2} \mathrm{O}(100): \mathrm{Cu}$ ] surfaces, as shown in Figs. 3(A) and 3(B). Moderate relaxation effects are seen for $\mathrm{Cu}_{2} \mathrm{O}(100)$ : O [Fig. 4(E)]. The $\mathrm{Cu}-\mathrm{O}$ bond distance $d_{\mathrm{Cu}-\mathrm{O}}$ at the surface is $1.76 \AA$, i.e., $6 \%$ shorter than the bulk value. Unlike the oxygen-terminated surface, $\mathrm{Cu}_{2} \mathrm{O}(100): \mathrm{Cu}$ experiences a rather drastic surface reconstruction, resulting in the outermost surface copper atoms coming much closer to
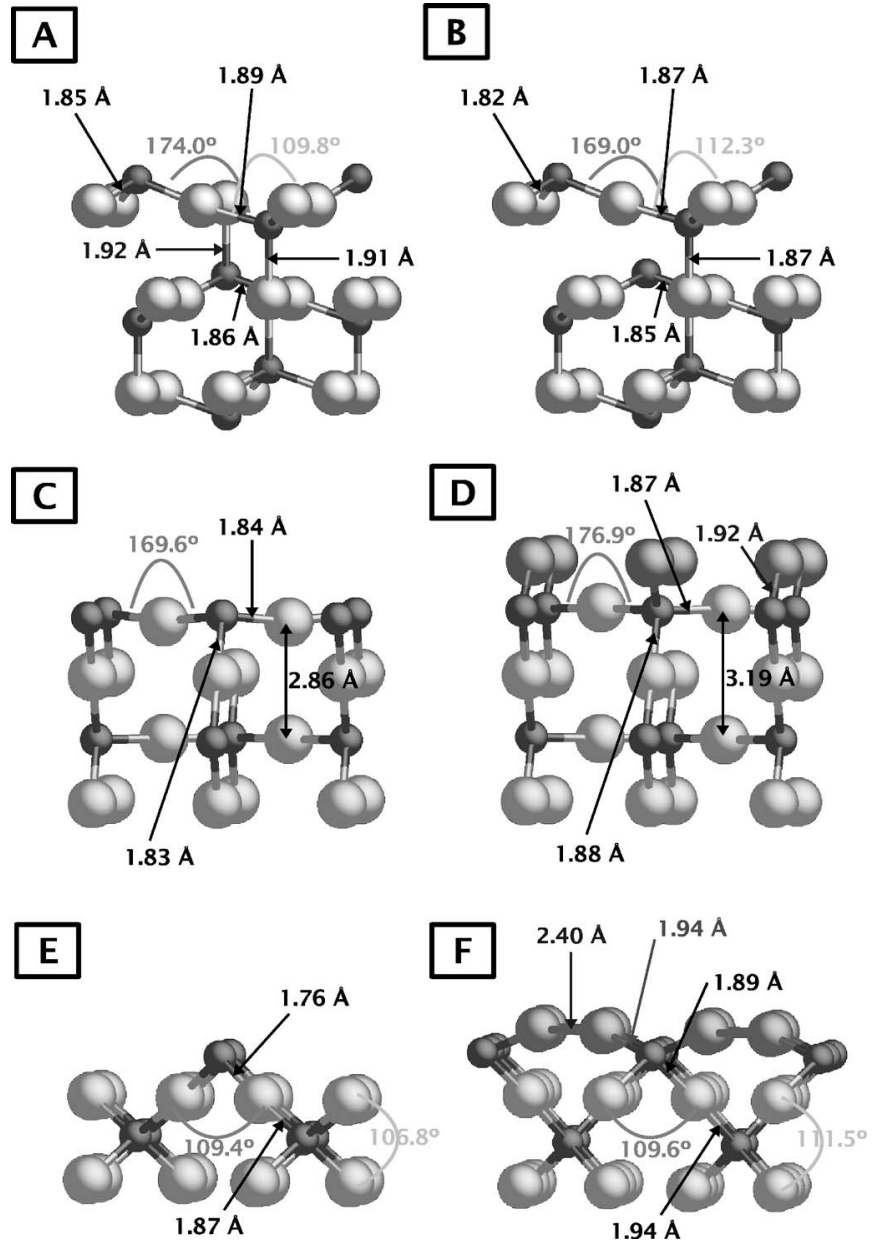

FIG. 4. Relaxed geometries of various $\mathrm{Cu}_{2} \mathrm{O}$ surfaces. (A) $\mathrm{Cu}_{2} \mathrm{O}(111)$, (B) $\mathrm{Cu}_{2} \mathrm{O}(111)-\mathrm{Cu}_{\text {CuS }}$, (C) $\mathrm{Cu}_{2} \mathrm{O}(110): \mathrm{CuO}$, (D) $\mathrm{Cu}_{2} \mathrm{O}(110): \mathrm{Cu}$, (E) $\mathrm{Cu}_{2} \mathrm{O}(100): \mathrm{O}$, and (F) $\mathrm{Cu}_{2} \mathrm{O}(100): \mathrm{Cu}$. (C) and (D) are viewed along the [001] direction. The optimized bond lengths and angles are labeled accordingly. Small dark spheres indicate oxygen atoms and large light ones, $\mathrm{Cu}$ atoms.

form copper dimer rows, with a $\mathrm{Cu}-\mathrm{Cu}$ bond distance $d_{\mathrm{Cu}-\mathrm{Cu}}$, of $2.40 \AA$ [Fig. 4(F)]. This is a 7\% contraction in bond distance as compared to the calculated bulk $d_{\mathrm{Cu}-\mathrm{Cu}}$.

Likewise, for the $\mathrm{Cu}_{2} \mathrm{O}(110)$ surface, we considered the two different surface terminations: $\mathrm{Cu}_{2} \mathrm{O}(110): \mathrm{CuO}$ [Figs. $3(\mathrm{~F})$ and $3(\mathrm{G})$ ], where the outermost layer contains both $\mathrm{Cu}$ and $\mathrm{O}$ surface atoms (labeled as $\mathrm{Cu}_{\mathrm{SUF}}$ and $\mathrm{O}_{\mathrm{SUF}}$, respectively), and $\mathrm{Cu}_{2} \mathrm{O}(110)$ : $\mathrm{Cu}$ [Fig. 3(C)], which is terminated by a reconstructed layer of $\mathrm{Cu}$ atoms. This surface consists of alternating $\mathrm{CuO}$ and $\mathrm{Cu}$ layers, and we can use a characteristic interlayer spacing between two consecutive $\mathrm{CuO}$ layers, $d_{\mathrm{CuO}-\mathrm{CuO}}$, to investigate relaxation effects between these layers. With a bulk spacing between two successive $\mathrm{CuO}$ planes, $d_{\mathrm{CuO}-\mathrm{CuO}}$ of $3.05 \AA, \quad \mathrm{Cu}_{2} \mathrm{O}(110): \mathrm{CuO}$ and $\mathrm{Cu}_{2} \mathrm{O}(110): \mathrm{Cu}$ exhibit somewhat different relaxation trends: The outermost interlayer $d_{\mathrm{CuO}-\mathrm{CuO}}$ found in $\mathrm{Cu}_{2} \mathrm{O}(110): \mathrm{CuO}$ is $2.86 \AA$, and that in $\mathrm{Cu}_{2} \mathrm{O}(110): \mathrm{Cu}$ is $3.19 \AA$, showing a $-6.3 \%$ and $+4.6 \%$ variation compared to the theoretical bulk spacing, respectively. The surface $d_{\mathrm{Cu}-\mathrm{O}}$ in both terminations also shows converse relaxation: $-1.6 \%$ for $\mathrm{Cu}_{2} \mathrm{O}(110): \mathrm{CuO}$ 
and $+2.7 \%$ for $\mathrm{Cu}_{2} \mathrm{O}(110)$ : $\mathrm{Cu}$. These effects are best illustrated in Figs. 4(C) and 4(D).

For the $\mathrm{Cu}_{2} \mathrm{O}(111)$ surface, we considered three different terminations: O-terminated $\left[\mathrm{Cu}_{2} \mathrm{O}(111): \mathrm{O}\right], \mathrm{Cu}$-terminated $\left[\mathrm{Cu}_{2} \mathrm{O}(111): \mathrm{Cu}\right]$ [Figs. 3(D) and 3(E)], and the stoichiometric surface, hereafter labeled as $\mathrm{Cu}_{2} \mathrm{O}(111)$ [see Figs. $3(\mathrm{H})$ and 3(I)]. The (111) surface consists of a basic threelayer lateral unit, with a copper layer sandwiched between two layers of oxygen atoms [see Fig. 3(I)]. We denote this $\mathrm{O}-\mathrm{Cu}-\mathrm{O}$ lateral unit as a trilayer, which is characteristic of the [111] surface direction. There are typically four distinct surface atoms in this structure, namely, the coordinatively saturated copper $\left(\mathrm{Cu}_{\mathrm{CSA}}\right)$ atom, the coordinatively unsaturated copper $\left(\mathrm{Cu}_{\mathrm{CUS}}\right)$ atom, the coordinatively saturated oxygen $\left(\mathrm{O}_{\mathrm{CSA}}\right)$ atom, and the coordinatively unsaturated oxygen $\left(\mathrm{O}_{\mathrm{CUS}}\right)$ atom, as shown in Fig. 3(H). Surface relaxations were found to be minimal and are depicted in Fig. 4(A). The $\mathrm{Cu}_{\mathrm{CSA}}-\mathrm{O}_{\mathrm{CUS}}$ bond length shrinks very slightly from 1.87 to $1.85 \AA$, while the vertical bond distance between $\mathrm{Cu}_{\mathrm{CUS}}$ and the topmost $\mathrm{O}$ atom found in second trilayer increases to $1.92 \AA$ (from $1.87 \AA$ ). Upon relaxation, this causes a more compact surface, where the oxygen atoms sink in and the copper atoms become more exposed.

Looking at these seven different nondefected $(1 \times 1)$ surface terminations, we notice that only one of them is stoichiometric [i.e., $\mathrm{Cu}_{2} \mathrm{O}(111)$ ], with the other six having either an excess of $\mathrm{Cu}$ or $\mathrm{O}$ atoms and thus belong to the class of so-called polar surfaces. ${ }^{48,49}$ In addition to these structures, we considered various surface structures containing defects created by removing from (or adding to) the ideal $(1 \times 1)$ structures single oxygen (or copper) atoms. For the $\mathrm{Cu}_{2} \mathrm{O}(111)$ surface, both antisites and adsorption of adatoms at surface interstitial sites are also considered. An antisite is created by replacing a surface $\mathrm{Cu}$ atom with an $\mathrm{O}$ atom, or vice versa, i.e., an oxygen in a metal atom site. To exemplify the creation of defects with some examples, we consider the $\mathrm{Cu}_{2} \mathrm{O}(111)-\mathrm{Cu}_{\mathrm{CUS}}$ structure; it consists of the stoichiometric $\mathrm{Cu}_{2} \mathrm{O}(111)$ surface with the $\mathrm{Cu}_{\text {CUS }}$ atom removed (hence the

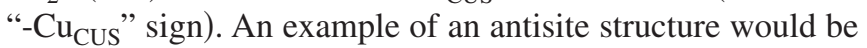
$\mathrm{Cu}_{2} \mathrm{O}(111)+\mathrm{Cu}_{\mathrm{O}_{\mathrm{CSA}}}$, where the $\mathrm{O}_{\mathrm{CSA}}$ atom is replaced by a $\mathrm{Cu}$ atom. Furthermore, $\mathrm{Cu}_{2} \mathrm{O}(111)+\mathrm{Cu}_{\mathrm{i}(\mathrm{SUF})}$ would indicate an additional $\mathrm{Cu}$ atom at the interstitial surface site of the $\mathrm{Cu}_{2} \mathrm{O}(111)$ surface. All considered surface structures and their corresponding surface energies (at both oxygen-rich and oxygen-lean conditions) are reported in Table I.

\section{Energetics and thermodynamics}

As mentioned above, we analyze the stability of these different oxide surfaces when in contact with an oxygen environment characterized by a given $\mathrm{O}$ chemical potential. This $\mu_{\mathrm{O}}(p, T)$ can only be varied experimentally within certain boundaries, assuming that thermodynamic equilibrium applies. The lower boundary, which will be called the O-lean limit, is defined by the decomposition of the oxide into copper metal and oxygen. An appropriate upper boundary for $\mu_{\mathrm{O}}$, on the other hand (O-rich limit), is given by gas phase conditions that are so rich in oxygen that oxygen condensa-
TABLE I. Surface free energies, cf. Eq. (2), of various considered $(1 \times 1)$ surface structures at corresponding stoichiometric ratio $R_{\mathrm{Cu} / \mathrm{O}}$, which is the ratio of the number of $\mathrm{Cu}$ atoms to that of oxygen in the surface structure. A stoichiometric surface will have $R_{\mathrm{Cu} / \mathrm{O}}=2$. Surface energies at both the oxygen-lean $\left(\gamma_{\text {lean }}\right)$ and oxygen-rich $\left(\gamma_{\text {rich }}\right)$ limits are reported in $\mathrm{eV} / \AA^{2}$.

\begin{tabular}{|c|c|c|c|}
\hline Surface structures & $R_{\mathrm{Cu} / \mathrm{O}}$ & $\gamma_{\text {lean }}$ & $\gamma_{\text {rich }}$ \\
\hline $\mathrm{Cu}_{2} \mathrm{O}(111)$ & 2.00 & 0.049 & 0.049 \\
\hline $\mathrm{Cu}_{2} \mathrm{O}(111): \mathrm{Cu}$ & 2.50 & 0.098 & 0.137 \\
\hline $\mathrm{Cu}_{2} \mathrm{O}(111): \mathrm{O}$ & 1.67 & 0.102 & 0.064 \\
\hline $\mathrm{Cu}_{2} \mathrm{O}(111)-\mathrm{Cu}_{\mathrm{CSA}}$ & 1.80 & 0.084 & 0.065 \\
\hline $\mathrm{Cu}_{2} \mathrm{O}(111)-\mathrm{Cu}_{\mathrm{CuS}}$ & 1.80 & 0.025 & 0.006 \\
\hline $\mathrm{Cu}_{2} \mathrm{O}(111)-\mathrm{O}_{\mathrm{CSA}}$ & 2.50 & 0.107 & 0.145 \\
\hline $\mathrm{Cu}_{2} \mathrm{O}(111)-\mathrm{O}_{\mathrm{CUS}}$ & 2.50 & 0.098 & 0.137 \\
\hline $\mathrm{Cu}_{2} \mathrm{O}(111)+\mathrm{O}_{\mathrm{Cu}_{\mathrm{CSA}}}$ & 1.50 & 0.150 & 0.092 \\
\hline $\mathrm{Cu}_{2} \mathrm{O}(111)+\mathrm{O}_{\mathrm{Cu}_{\mathrm{CUS}}}$ & 1.50 & 0.121 & 0.063 \\
\hline $\mathrm{Cu}_{2} \mathrm{O}(111)+\mathrm{Cu}_{\mathrm{O}_{\mathrm{CSA}}}$ & 2.75 & 0.151 & 0.209 \\
\hline $\mathrm{Cu}_{2} \mathrm{O}(111)+\mathrm{Cu}_{\mathrm{O}_{\mathrm{CUS}}}$ & 2.75 & 0.134 & 0.192 \\
\hline $\mathrm{Cu}_{2} \mathrm{O}(111)+\mathrm{Cu}_{\mathrm{i}(\mathrm{SUF})}$ & 2.20 & 0.022 & 0.041 \\
\hline $\mathrm{Cu}_{2} \mathrm{O}(111)+\mathrm{O}_{\mathrm{i}(\mathrm{SUF})}$ & 1.67 & 0.091 & 0.053 \\
\hline $\mathrm{Cu}_{2} \mathrm{O}(110): \mathrm{CuO}$ & 1.89 & 0.026 & 0.003 \\
\hline $\mathrm{Cu}_{2} \mathrm{O}(110): \mathrm{Cu}$ & 2.11 & 0.112 & 0.135 \\
\hline $\mathrm{Cu}_{2} \mathrm{O}(110): \mathrm{CuO}-\mathrm{Cu}_{\mathrm{CSA}}$ & 1.78 & 0.091 & 0.044 \\
\hline $\mathrm{Cu}_{2} \mathrm{O}(110): \mathrm{CuO}-\mathrm{O}_{\mathrm{CuS}}$ & 2.13 & 0.086 & 0.109 \\
\hline $\mathrm{Cu}_{2} \mathrm{O}(100): \mathrm{Cu}$ & 2.25 & 0.098 & 0.131 \\
\hline $\mathrm{Cu}_{2} \mathrm{O}(100): \mathrm{O}$ & 1.80 & 0.067 & 0.034 \\
\hline $\mathrm{Cu}_{2} \mathrm{O}(100): \mathrm{Cu}-\mathrm{Cu}_{\mathrm{CUS}}$ & 2.00 & 0.076 & 0.076 \\
\hline $\mathrm{Cu}_{2} \mathrm{O}(100): \mathrm{Cu}-\mathrm{O}_{\mathrm{CSA}}$ & 3.00 & 0.140 & 0.240 \\
\hline $\mathrm{Cu}_{2} \mathrm{O}(100): \mathrm{O}-\mathrm{Cu}_{\mathrm{CSA}}$ & 1.60 & 0.113 & 0.046 \\
\hline $\mathrm{Cu}_{2} \mathrm{O}(100): \mathrm{O}-\mathrm{O}_{\mathrm{CSA}}$ & 2.25 & 0.124 & 0.158 \\
\hline
\end{tabular}

tion will start on the surface at low enough temperatures. Reasonable and well-defined estimates for these limits are given by ${ }^{32}$

$$
\Delta H_{f}(p=0, T=0 \mathrm{~K})<\Delta \mu_{\mathrm{O}}\left(p_{\mathrm{O}_{2}}, T\right)<0,
$$

where the $\mathrm{O}$ chemical potential is referenced with respect to the total energy of an oxygen molecule, $\Delta \mu_{\mathrm{O}}$ $=\mu_{\mathrm{O}}-(1 / 2) E_{\mathrm{O}_{2}}^{\text {total }}$, and $\Delta H_{f}(p=0, T=0 \mathrm{~K})$ is the lowtemperature limit for the heat of formation of $\mathrm{Cu}_{2} \mathrm{O}$. To also consider the uncertainty in these theoretically well-defined, but appropriate, limits for $\Delta \mu_{\mathrm{O}}$, we plot the dependence of the surface free energy for regions outside of these boundaries. From this it will be apparent that the uncertainty in the boundaries does not affect the physical conclusions drawn.

All the calculated surface energies are shown in Fig. 5. Oxygen-rich terminations (i.e., having more $\mathrm{O}$ atoms than the stoichiometric surface) show a negative slope, while the copper-rich terminations show a positive slope. This indicates that the former terminations are more favorable in an oxygen-rich gaseous environment, and the latter in an oxygen-lean environment. Comparing the results in Fig. 5, it becomes apparent that two structures exhibit very low sur- 
face energies under oxygen-rich conditions, namely,

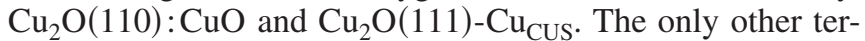
mination that shows a comparatively low surface energy (under oxygen-lean conditions) is the $\mathrm{Cu}_{2} \mathrm{O}(111)+\mathrm{Cu}_{\mathrm{i}}(\mathrm{SUF})$ structure, which is the stoichiometric $\mathrm{Cu}_{2} \mathrm{O}(111)$ surface with an additional interstitial surface copper atom $\left(\mathrm{Cu}_{\mathrm{i}(\mathrm{SUF})}\right)$ sitting directly above the $\mathrm{O}_{\mathrm{CSA}}$. The commonly used electrostatic model of Tasker ${ }^{48}$ to explain the energetic stability of surfaces assumes that the charge state and chemical environment for all atoms of the same species are exactly identical (i.e., regardless whether they are at the surface or in the bulk), and clearly this is not adequate and is over-ruled when structural and electronic relaxation at the surface is allowed. Hence, the so-called polar surfaces could well be stabilized as in this case and could be important in certain catalytic reactions. It can also be seen that all other considered surface structures are much higher in energy (shown as pale gray lines in Fig. 5), making them less probable to participate as catalytically active sites.

Experimentally, many unique morphologies of $\mathrm{Cu}_{2} \mathrm{O}$ crystals have been synthesized by controlling and manipulating the growth medium. ${ }^{50-57}$ Recently, Xu et al. ${ }^{57}$ studied the growth of $\mathrm{Cu}_{2} \mathrm{O}$ nanocrystals, and by varying the ratio of the concentration of aqueous ammonia to that of copper ions $\left(R_{1}\right)$, they were able to investigate the influence of the growth medium on various morphologies. This study found that $R_{1}=7$ yielded an octahedra morphology (bounded by eight $\{111\}$ planes). This shape was attributed to the different growth rates along the $\langle 100\rangle$ versus the $\langle 111\rangle$ directions. By growing $\mathrm{Cu}_{2} \mathrm{O}$ crystals in a sodium hydroxide solution (without any aqueous ammonia), the growth rates of the various directions were almost identical, hence yielding a spherical morphology. When $R_{1}$ was set to 4 , cubelike nanostructures were seen. Following this work, Siegfried and $\mathrm{Choi}^{56}$ used electrochemical means to systematically study the role of artificial additives on the growth of various crystallographic planes. Using a combination of sodium and ammonium cations and nitrate and sulfate anions, the authors showed that the growth dependence of the low-index planes was indeed complex and could be used to tune the required well-defined crystal shapes.

With the calculated surface free energies of the different $(1 \times 1) \mathrm{Cu}_{2} \mathrm{O}$ terminations, we attempt to build a (theoretical) Wulff construction ${ }^{58}$ for the $\mathrm{Cu}_{2} \mathrm{O}$ single crystal. This construction is constrained to only the considered $(1 \times 1)$ $\mathrm{Cu}_{2} \mathrm{O}$ terminations, and thus its purpose is to compare the relative surface energies rather than to predict the actual equilibrium shape of crystalline $\mathrm{Cu}_{2} \mathrm{O}$. Having said that, the Wulff octahedra that we construct (Fig. 6, left) is fairly similar to what is observed experimentally. ${ }^{57}$ Since the surface free energy that we calculated is a function of the oxygen chemical potential, the obtained construction could be varied within the proposed oxygen limits. In Fig. 6, we show the Wulff shapes for the two considered limits, i.e., under oxygen-lean and oxygen-rich conditions.

It is evident from the thermodynamic stability plot in Fig. 5 that the lowest-energy structure at the oxygen-rich limit is $\mathrm{Cu}_{2} \mathrm{O}(110): \mathrm{CuO}$ and it appears as the dominating facet. At the oxygen-lean limit, another competing surface,

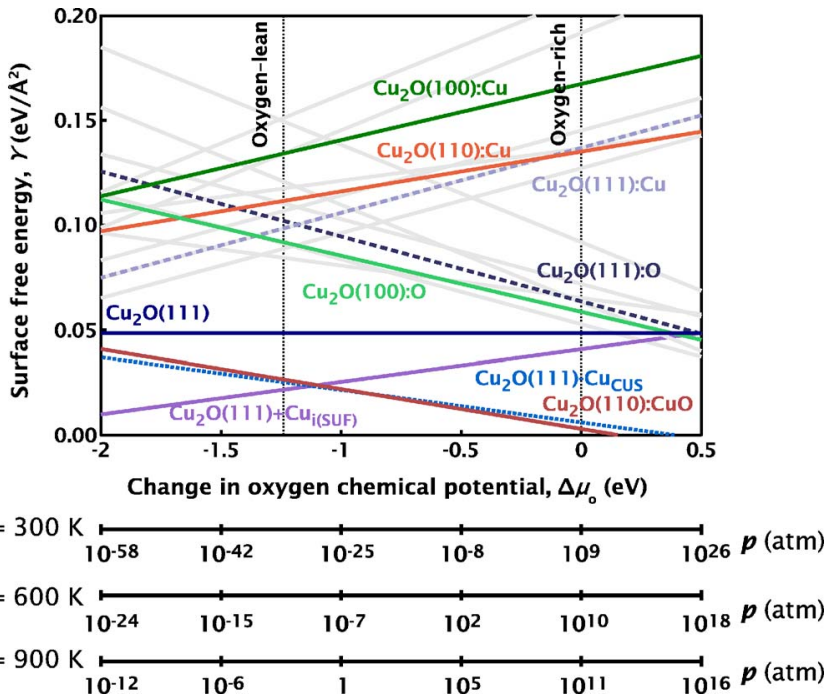

FIG. 5. (Color online) Calculated surface free energy of various considered $\mathrm{Cu}_{2} \mathrm{O}$ surfaces as a function of the change in oxygen chemical potential, $\Delta \mu_{\mathrm{O}}$, with the corresponding pressure bar lines at $T=300,600$, and $900 \mathrm{~K}$. Two competing low-energy structures $\left[\mathrm{Cu}_{2} \mathrm{O}(110): \mathrm{CuO}\right.$ and $\left.\mathrm{Cu}_{2} \mathrm{O}(111)-\mathrm{Cu}_{\mathrm{CUS}}\right]$ are found under typical technical catalytic conditions of $T \sim 520 \mathrm{~K}$ and $p \sim 1-25 \mathrm{~atm}$. Unfavorable surface phases are indicated by pale gray lines.

$\mathrm{Cu}_{2} \mathrm{O}(111)+\mathrm{Cu}_{\mathrm{i}(\mathrm{SUF})}$, is marginally more stable and hence manifested as a larger facet in the Wulff construction. All other studied terminations do not show up in the present construction as the corresponding planes lie outside of this octahedron and do not intersect at any point. Due to the limitation of restricting this investigation to the $(1 \times 1)$ terminations, we do not include possible reconstruction of the surface, which could well lower the surface free energy of any $\mathrm{Cu}_{2} \mathrm{O}$ terminations and consequently have a significant effect on the overall shape of the Wulff construction. However, the low-energy structures exhibit rather small surface free energies (i.e. close to $0 \mathrm{eV} / \AA^{2}$ ), and we are confident that further lowering of surface free energies is rather unlikely for this case.

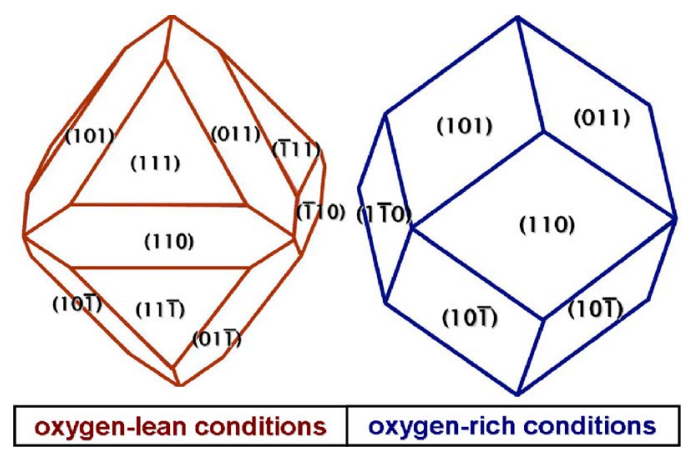

FIG. 6. (Color online) Wulff construction of the $\mathrm{Cu}_{2} \mathrm{O}$ crystal under oxygen-lean (left) and oxygen-rich (right) conditions. These shapes are constructed by considering the $(1 \times 1)$ terminations and therefore only reflect the relative surface energies of various oxide surfaces considered in this work. These shapes could be different from those observed in the real $\mathrm{Cu}_{2} \mathrm{O}$ crystal, which are sensitively dependent on the way the crystal is synthesized. 


\section{Electronic structure}

Having identified the low-energy surface structures of $\mathrm{Cu}_{2} \mathrm{O}$ under both oxygen-lean and oxygen-rich conditions, we investigate the electronic structure of these surfaces. The projected density of states (pDOS) of the following structures is shown in Fig. 7: $\mathrm{Cu}_{2} \mathrm{O}(111)+\mathrm{Cu}_{\mathrm{i}(\mathrm{SUF})}$, $\mathrm{Cu}_{2} \mathrm{O}(110): \mathrm{CuO}, \mathrm{Cu}_{2} \mathrm{O}(111)-\mathrm{Cu}_{\mathrm{CuS}}, \mathrm{Cu}_{2} \mathrm{O}(111)$, and bulk $\mathrm{Cu}_{2} \mathrm{O}$. Beginning with the bulk oxide [Fig. 7(E)], we can see two distinct bands: one extending from -5 to $-7.5 \mathrm{eV}$ and the other slightly below the Fermi level to $-5 \mathrm{eV}$. The former shows predominantly $\mathrm{O} 2 p$ character and the latter $\mathrm{Cu} 3 d$ character. There exists a very small band gap of $0.64 \mathrm{eV}$, reflecting the semiconducting nature of $\mathrm{Cu}_{2} \mathrm{O}$. Moving from the bulk phase to surface structures, we observe a few distinct features in the pDOS. For the $\mathrm{Cu}_{2} \mathrm{O}(111)$ structure [Fig. 7(D)], a slight broadening of the hybridized $\mathrm{O} 2 p-\mathrm{Cu} 3 d$ band $(-4$ to $-7 \mathrm{eV}$ ) and a narrowing of the $\mathrm{Cu} 3 d$ band is observed. While still retaining the semiconducting nature of its parent bulk phase, an additional appearance of a small unoccupied $\mathrm{Cu}_{\text {CUS }} 3 d$ band can be seen at $0.5 \mathrm{eV}$, reflecting an incomplete filling of the $3 d$ shell of copper.

Turning to the $\mathrm{Cu}_{2} \mathrm{O}(111)-\mathrm{Cu}_{\text {CUS }}$ structure [Fig. 7(C)], we see a shift of both the hybridized $\mathrm{O} 2 p-\mathrm{Cu} 3 d$ band and $\mathrm{Cu}_{\mathrm{CSA}} 3 d$ band to higher energy (i.e., toward the Fermi level) and the disappearance of the band gap. From the pDOS, we see that the states near the Fermi level are predominantly $\mathrm{O} 2 p$ in character. This metallic character is not found in the previously discussed stoichiometric $\mathrm{Cu}_{2} \mathrm{O}(111)$ surface. For the stoichiometric $\mathrm{Cu}_{2} \mathrm{O}(111)$ structure, a small unoccupied state at about $0.5 \mathrm{eV}$ above the Fermi level can be seen. On plotting the wave functions at the $\Gamma$ point of the states giving rise to this feature (not shown), we find they are rather similar to those responsible for the peak at the Fermi level of the $\mathrm{Cu}_{2} \mathrm{O}(111)-\mathrm{Cu}_{\mathrm{CUS}}$ structure, being distributed on bulk $\mathrm{O}$ and $\mathrm{Cu}$ atoms [see Fig. 8 (left)]. The nature of the electronic bands are also qualitatively similar.

Looking at the pDOS of the other competing low-energy structure, $\mathrm{Cu}_{2} \mathrm{O}(110)$ : $\mathrm{CuO}$ [Fig. 7(B)], under oxygen-rich conditions, we find that the hybridized $\mathrm{O} 2 p-\mathrm{Cu} 3 d$ band shifts substantially to higher energy and the position of the surface $\mathrm{Cu} 3 d$ band is comparable to that of the $\mathrm{Cu}_{2} \mathrm{O}(111)-\mathrm{Cu}_{\mathrm{CUS}}$ structure. The distinct peak at the Fermi level indicates that this surface is metallic as well. However, this peak at the Fermi level is significantly higher and has a predominantly different orbital character from that of the $\mathrm{Cu}_{2} \mathrm{O}(111)-\mathrm{Cu}_{\mathrm{CUS}}$ structure. From the wave-function plots in Fig. 8 (right), we can see that this metallic character is truly induced by surface atoms. To investigate if this metallic behavior is an artifact due to a small surface unit-cell constraint, we recalculate this structure using a $(2 \times 2)$ surface cell and remove any symmetry constraints. Upon doing so, the distinct peak at the Fermi level remains, confirming that this metallic state is a genuine electronic effect at the surface, not influenced by the surface unit-cell size and symmetry.

Considering the low-energy structure at the oxygen-lean limit, we find that for the pDOS of the $\mathrm{Cu}_{2} \mathrm{O}(111)$ $+\mathrm{Cu}_{\mathrm{i}(\mathrm{SUF})}$ structure [Fig. 7(A)], the hybridized $\mathrm{O} 2 p$-Cu $3 d$
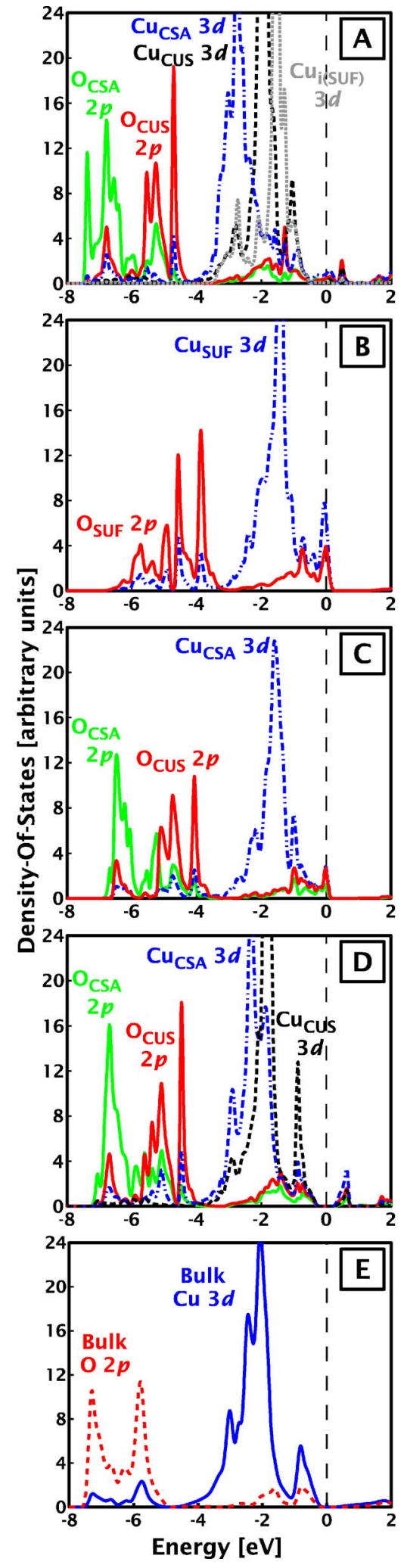

FIG. 7. (Color online) Projected density of states for the various oxide surface structures and bulk oxide phase. From top to bottom: $\mathrm{Cu}_{2} \mathrm{O}(111)+\mathrm{Cu}_{\mathrm{i}(\text { SUF })}, \quad \mathrm{Cu}_{2} \mathrm{O}(110): \mathrm{CuO}, \quad \mathrm{Cu}_{2} \mathrm{O}(111)-\mathrm{Cu}_{\mathrm{CUS}}$, $\mathrm{Cu}_{2} \mathrm{O}(111)$, and bulk $\mathrm{Cu}_{2} \mathrm{O}$. The Fermi energy is indicated by the vertical dashed line at $0 \mathrm{eV}$. 

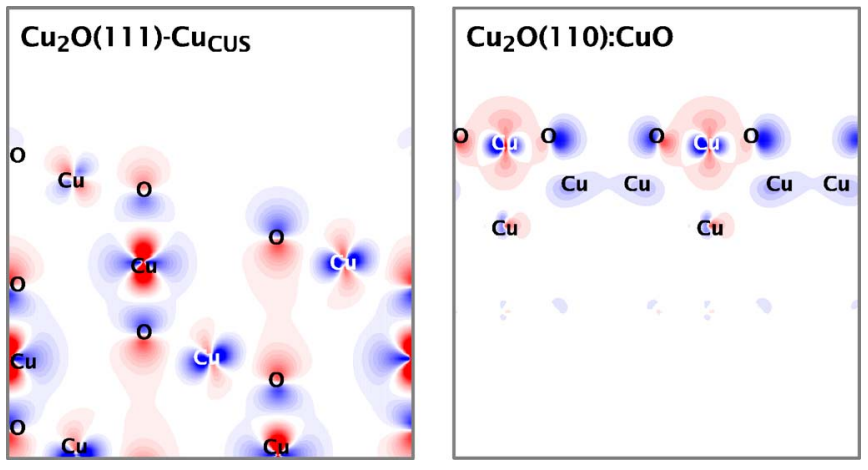

FIG. 8. (Color online) Contour plots of the wave function of the $\mathrm{Cu}_{2} \mathrm{O}(111)-\mathrm{Cu}_{\mathrm{CuS}}$ (left) and $\mathrm{Cu}_{2} \mathrm{O}(110): \mathrm{CuO}$ (right) structures at the Fermi level, sampled at the $\Gamma$ point. The positions of the $\mathrm{Cu}$ and $\mathrm{O}$ atoms are labeled.

band is not shifted with respect to that of bulk $\mathrm{Cu}_{2} \mathrm{O}$ (i.e., from -5 to $-7.5 \mathrm{eV}$ ) but is slightly broadened. The $3 d$ bands of $\mathrm{Cu}_{\mathrm{i} \text { (SUF) }}, \mathrm{Cu}_{\mathrm{CSA}}$, and $\mathrm{Cu}_{\mathrm{CUS}}$ are shifted to lower energies and narrowing of bands is evident. This structure is also metallic, like $\mathrm{Cu}_{2} \mathrm{O}(110): \mathrm{CuO}$ and $\mathrm{Cu}_{2} \mathrm{O}(111)-\mathrm{Cu}_{\mathrm{CUS}}$, although the states at the Fermi level are less pronounced than those found in the other two structures.

In hope of understanding the (de)polarization effects at these oxide surfaces, we have also calculated the work function $\Phi$ for the low-energy surfaces, defined according to Eq. (6),

$$
\Phi=V_{\infty}-E_{F},
$$

where $V_{\infty}$ and $E_{F}$ are the electrostatic potential at infinity (i.e., in the vacuum of the slab) and the Fermi energy, respectively. The calculated values are reported in Table II with varying $R_{\mathrm{Cu} / \mathrm{O}}$.

The work function is a direct consequence of the electrostatic barrier induced by the dipole double layer at the surface. ${ }^{59}$ The presence of highly electronegative atoms, such as oxygen, at the surface increases the contribution of the dipole double layer to this electrostatic barrier, making it harder for an electron to leave the surface. This is reflected in the work functions of both the oxygen-rich stoichiometry surfaces [i.e., the $\mathrm{Cu}_{2} \mathrm{O}(111)-\mathrm{Cu}_{\mathrm{CUS}}$ and the $\mathrm{Cu}_{2} \mathrm{O}(110): \mathrm{CuO}$ structures], which have values higher than that of the stoichiometric $\mathrm{Cu}_{2} \mathrm{O}(111)$ surface. Conversely, the work function of the copper-rich $\mathrm{Cu}_{2} \mathrm{O}(111)+\mathrm{Cu}_{\mathrm{i} \text { (SUF) }}$ structure is smaller in value when compared to that of the $\mathrm{Cu}_{2} \mathrm{O}(111)$ surface.

By comparing the electronic structure of the two lowenergy structures favored under oxygen-rich conditions, we find that although they have a very similar low surface free energy, their electronic structures are rather different.
TABLE II. Work functions, cf. Eq. (6), for the low-energy structures at both the oxygen-rich and oxygen-lean limits.

\begin{tabular}{lcc}
\hline \hline Surface structures & $R_{\mathrm{Cu} / \mathrm{O}}$ & $\begin{array}{c}\Phi \\
(\mathrm{eV})\end{array}$ \\
\hline $\mathrm{Cu}_{2} \mathrm{O}(111)-\mathrm{Cu}_{\mathrm{CUS}}$ & 1.80 & 5.36 \\
$\mathrm{Cu}_{2} \mathrm{O}(111)$ & 2.00 & 4.58 \\
$\mathrm{Cu}_{2} \mathrm{O}(111)+\mathrm{Cu}_{\mathrm{i}(\mathrm{SUF})}$ & 2.20 & 4.08 \\
$\mathrm{Cu}_{2} \mathrm{O}(110): \mathrm{CuO}$ & 1.89 & 5.89 \\
\hline \hline
\end{tabular}

$\mathrm{Cu}_{2} \mathrm{O}(111)-\mathrm{Cu}_{\mathrm{CUS}}$ structure's metallic character is largely bulk-like in nature, whereas that of the $\mathrm{Cu}_{2} \mathrm{O}(110): \mathrm{CuO}$ structure is truly surface-like. It is noteworthy to mention that from a parent bulk phase that is semiconducting, all the low-energy surfaces found are metallic in character for the range of oxygen chemical potential considered. Having such low surface free energies, these terminations could well be stabilized at the surface of the catalytic material and might offer different active sites in the reaction.

\section{SUMMARY AND CONCLUSION}

In this work, we performed density-functional theory calculations for the (100), (110), and (111) low-index surfaces of copper oxide, $\mathrm{Cu}_{2} \mathrm{O}$. We calculated the surface free energy for various surface terminations and presented these energies as a function of the oxygen chemical potential. We have shown that three surfaces, none of which are stoichiometric, namely, (1) the $\mathrm{Cu}_{2} \mathrm{O}(111)-\mathrm{Cu}_{\mathrm{CUS}}$ structure, (2) the $\mathrm{Cu}_{2} \mathrm{O}(110): \mathrm{CuO}$ structure, and (3) the $\mathrm{Cu}_{2} \mathrm{O}(111)+\mathrm{Cu}_{\mathrm{i}(\mathrm{SUF})}$ structure, exhibit the lowest surface free energy for the considered range of oxygen chemical potential. Under oxygen-rich conditions, both the $\mathrm{Cu}_{2} \mathrm{O}(111)-\mathrm{Cu}_{\mathrm{CUS}}$ structure and the $\mathrm{Cu}_{2} \mathrm{O}(110): \mathrm{CuO}$ structure are favored, while the $\mathrm{Cu}_{2} \mathrm{O}(111)+\mathrm{Cu}_{\mathrm{i}(\mathrm{SUF})}$ structure is the most stable under oxygen-lean conditions. Apart from defying Tasker's argument of instability due to surface polarity, these low-energy structures were found to be metallic in character. By offering a different geometric and electronic structure to the stoichiometric surface, we propose that they could play an important role in heterogeneous catalytic oxidation reactions such as the OWGS reaction.

\section{ACKNOWLEDGMENTS}

The authors gratefully acknowledge support from the Australian Research Council (ARC), the Australian Institute of Physics (AIP), the Australian Partnership for Advanced Computing (APAC), and the Australian Centre for Advanced Computing and Communication (ac3). 
*Corresponding author. Electronic address:

aloysius@physics.usyd.edu.au

${ }^{1}$ X. D. Peng and M. A. Barteau, Langmuir 7, 1426 (1991).

${ }^{2}$ M. A. Barteau, Chem. Rev. (Washington, D.C.) 96, 1413 (1996).

${ }^{3}$ M. Calatayud, A. Markovits, M. Menetrey, B. Mguig, and C. Minot, Catal. Today 85, 125 (2003).

${ }^{4}$ C. Stampfl, Catal. Today 105, 17 (2005).

${ }^{5}$ A. F. Ghenciu, Curr. Opin. Solid State Mater. Sci. 6, 389 (2002).

${ }^{6}$ J. Zalc and D. Löffler, J. Power Sources 11, 58 (2002).

${ }^{7}$ G. Jacobs, P. M. Patterson, L. Williams, E. Chenu, D. Sparks, G. Thomas, and B. H. Davis, Appl. Catal., A 262, 171 (2004).

${ }^{8}$ X. Qi and M. Flytzani Stephanopoulos, Ind. Eng. Chem. Res. 43, 2005 (2004).

${ }^{9}$ G. Jacobs, L. Williams, U. Graham, G. A. Thomas, D. E. Sparks, and B. H. Davis, Appl. Catal., A 252, 107 (2003).

${ }^{10}$ T. Utaka, K. Sekizawa, and K. Eguchi, Appl. Catal., A 194/195, 21 (2000).

${ }^{11}$ Y. Tanaka, T. Utaka, R. Kikuchi, K. Sasaki, and K. Eguchi, Appl. Catal., A 238, 11 (2002).

${ }^{12}$ J. L. Ayastuy, M. A. Gutiérrez-Ortiz, J. A. González-Marcos, A. Aranzabal, and J. González-Velasco, Ind. Eng. Chem. Res. 44, 41 (2005).

${ }^{13}$ E. S. Bickford, S. Velu, and C. Song, Catal. Today 99, 347 (2005).

${ }^{14}$ Y. Xu and M. Mavrikakis, Surf. Sci. 494, 131 (2001).

${ }^{15}$ G. Ertl, Surf. Sci. 6, 208 (1967).

${ }^{16}$ A. Spitzer and H. Luth, Surf. Sci. 118, 136 (1982).

${ }^{17}$ R. W. Judd, P. Hollins, and J. Pritchard, Surf. Sci. 171, 643 (1986).

${ }^{18}$ M. K. Rajumon and C. N. R. R. K. Prabhakaran, Surf. Sci. 233, L237 (1990).

${ }^{19}$ H. Niehus, Surf. Sci. 130, 41 (1983).

${ }^{20}$ J. Haase and H. J. Kuhr, Surf. Sci. 203, L695 (1988).

${ }^{21}$ B. Luo and J. Urban, J. Phys.: Condens. Matter 3, 2873 (1991).

${ }^{22}$ R. L. Toomes, D. P. Woodruff, M. Polcik, S. Bao, P. Hofmann, and K. M. Schindler, Surf. Sci. 443, 300 (2000).

${ }^{23}$ F. Jensen, F. Besenbacher, E. Lægsgaard, and I. Stensgaard, Surf. Sci. 259, L774 (1991).

${ }^{24}$ S. M. Johnston, A. Mulligan, V. Dhanak, and M. Kadodwala, Surf. Sci. 519, 57 (2002).

${ }^{25}$ T. Matsumoto, R. Bennett, P. Stone, T. Yamada, K. Domen, and M. Bowker, Surf. Sci. 471, 225 (2001).

${ }^{26}$ S. Y. Lee, N. Mettlach, N. Nguyen, and J. M. W. Y. M. Sun, Appl. Surf. Sci. 206, 102 (2003).

${ }^{27}$ L. Zhou, S. Günther, D. Moszynski, and R. Imbihl, J. Catal. 235, 359 (2005).

${ }^{28}$ A. Soon, M. Todorova, B. Delley, and C. Stampfl, Phys. Rev. B 73, 165424 (2006).

${ }^{29}$ J. P. Perdew, K. Burke, and M. Ernzerhof, Phys. Rev. Lett. 77,
3865 (1996).

${ }^{30}$ B. Delley, J. Chem. Phys. 92, 508 (1990).

${ }^{31}$ B. Delley, J. Chem. Phys. 113, 7756 (2000).

${ }^{32}$ K. Reuter and M. Scheffler, Phys. Rev. B 65, 035406 (2002).

${ }^{33}$ K. Reuter and M. Scheffler, Phys. Rev. Lett. 90, 046103 (2003).

${ }^{34}$ K. Reuter and M. Scheffler, Phys. Rev. B 68, 045407 (2003).

${ }^{35}$ W. X. Li, C. Stampfl, and M. Scheffler, Phys. Rev. B 68, 165412 (2003).

${ }^{36}$ C. Stampfl, M. V. Ganduglia-Pirovano, K. Reuter, and M. Scheffler, Surf. Sci. 500, 368 (2002).

${ }^{37}$ C. Kittel, Introduction to Solid State Physics (Wiley, New York, 1996).

${ }^{38}$ J. Rogal, K. Reuter, and M. Scheffler, Phys. Rev. B 69, 075421 (2004)

${ }^{39}$ E. Ruiz, S. Alvarez, P. Alemany, and R. A. Evarestov, Phys. Rev. B 56, 7189 (1997).

${ }^{40}$ W. G. Wickoff, Crystal Structures (Wiley-Interscience, New York, 1960), Vol. 1.

${ }^{41}$ A. F. Wells, Structural Inorganic Chemistry, 5th ed. (Clarendon, Oxford, 1984).

${ }^{42}$ A. Werner and H. D. Hochheimer, Phys. Rev. B 25, 5929 (1982).

${ }^{43}$ D. R. Lide, CRC Handbook of Chemistry and Physics, Internet version 2005 (CRC, Boca Raton, FL, 2005).

${ }^{44}$ W. X. Li, C. Stampfl, and M. Scheffler, Phys. Rev. B 65, 075407 (2002).

${ }^{45}$ M. Todorova, K. Reuter, and M. Scheffler, J. Phys. Chem. B 108, 14477 (2004).

${ }^{46}$ M. V. Ganduglia-Pirovano and M. Scheffler, Phys. Rev. B 59, 15533 (1999).

${ }^{47}$ K. Huber and G. Herzberg, Molecular Spectra and Molecular Structure IV: Constants of Diatomic Molecules (Van Nostrand Reinhold, New York, 1979).

${ }^{48}$ P. W. Tasker, J. Phys. C 12, 4977 (1979).

${ }^{49}$ C. Noguera, J. Phys.: Condens. Matter 12, R367 (2000).

${ }^{50}$ W. Z. Wang, G. H. Wang, X. S. Wang, Y. J. Zhan, Y. K. Liu, and C. L. Zheng, Adv. Mater. (Weinheim, Ger.) 14, 67 (2002).

${ }^{51}$ D. B. Wang, M. S. Mo, D. B. Yu, L. Q. Xu, F. Q. Li, and Y. T. Qian, Cryst. Growth Des. 3, 231 (2003).

${ }^{52}$ L. F. Gou and C. J. Murphy, Nano Lett. 3, 231 (2003).

${ }^{53}$ M. Yang and J. J. Zhu, J. Cryst. Growth 256, 134 (2003).

${ }^{54}$ Y. Chang, J. J. Teo, and H. C. Zeng, Langmuir 21, 1074 (2005).

${ }^{55}$ R. Liu, F. Oba, E. W. Bohannan, F. Ernst, and J. A. Switzer, Chem. Mater. 15, 4882 (2003).

${ }^{56}$ M. J. Siegfried and K.-S. Choi, J. Am. Chem. Soc. 128, 10356 (2006).

${ }^{57}$ H. Xu, W. Wang, and W. Zhu, J. Phys. Chem. B 110, 13834 (2006).

${ }^{58}$ G. Wulff, Z. Kristallogr. 34, 449 (1901).

${ }^{59}$ N. D. Lang and W. Kohn, Phys. Rev. B 3, 1215 (1971). 